\title{
CONCEPÇÕES DOCENTES ACERCA DO FRACASSO E SUCESSO ESCOLAR DE ALUNOS DO ENSINO FUNDAMENTAL
}

\section{TEACHING CONCEPTS ABOUT THE FAILURE AND SUCCESS OF STUDENTS IN ELEMENTARY TEACHING}

\section{CONCEPCIONES DOCENTES ACERCA DEL FRACASO Y SUCESO ESCOLAR DE ALUMNOS DE LA ENSEÑANZA FUNDAMENTAL}

\author{
Thalyse Santana Pereira * \\ Stefânia Siqueira Martins Batista ** \\ Heron Laiber Bonadiman ***
}

\begin{abstract}
Resumo: O artigo descreve e analisa os principais resultados de pesquisa de iniciação científica sobre as concepções e métodos de avaliação escolar realizada por professores no contexto dos conselhos de classe de uma escola pública estadual do município de Lavras - MG. Foi realizado um estudo de caso único, e os materiais de pesquisa foram coletados através de observação participante, entrevistas, análise de documentos da secretaria escolar e construção de diário de campo. As reuniões de conselho de classe analisadas permitiram observar práticas de avaliação que utilizam juízos valorativos em detrimento de juízos técnicos acerca da construção de saberes escolares, interferindo direta e negativamente na história escolar dos alunos e alunas. Destarte, o fenômeno estudado possui relação direta com o insucesso escolar.
\end{abstract}

Palavras-Chave: Conselho de classe. Fracasso escolar. Fnsino fundamental

\begin{abstract}
This article describes and analyzes the main scientific research results on the concepts and methods of school assessment by teachers in the context of class councils in a state public school in the city of Lavras - MG. One single case of study was made and its data was collected through local observation, surveys, analysis of school documents and a field diary. The council meetings analyzed allowed us to observe the class assessment practices that use value judgments instead of technical judgments about the construction of school knowledge, interfering directly and negatively in the school history of students. Thus, the phenomenon studied has direct relationship with school failure.
\end{abstract}

Keywords: Class council. School failing. Elementary school.

\footnotetext{
* Graduanda em Psicologia pelo Centro Universitário de Lavras. thalysedid@hotmail.com

** Graduanda em Psicologia pelo Centro Universitário de Lavras stefania.siqueira@hotmail.com

*** Professor auxiliar da Universidade Federal dos Vales do Jequitinhonha e Mucuri. Doutorando em Psicologia pela PUC Minas heronbonadiman@gmail.com
} 
Resumen: El artículo describe y analiza los principales resultados de pesquisa de iniciación científica sobre las concepciones y métodos de evaluación escolar realizada por profesores en el contexto de los consejos de clase de una escuela pública estadual del municipio de Lavras MG. Fue realizado un estudio de caso único, y los materiales de pesquisa fueron colectados a través de observación participante, entrevistas, análisis de documentos de la secretaría escolar y construcción de diario de campo. Las reuniones de consejo de clase analizadas permitieron observar prácticas de evaluación que utilizan juicios valorativos en detrimento de juicios técnicos acerca de la construcción de saberes escolares, interfiriendo directa e negativamente en la historia escolar de los alumnos y alumnas. De esa manera, el fenómeno estudiado posee relación directa con el fracaso escolar.

Palabras-clave: consejo de clase. Fracaso escolar. Enseñanza fundamenta.

\section{Introdução}

O artigo descreve os resultados de um estudo qualitativo acerca das práticas e concepções dos professores acerca do fracasso escolar, de como referendam e denotam a aprovação e reprovação em alunos do Ensino Fundamental de uma escola estadual do município de Lavras- MG.

O fracasso escolar configura-se como tema de relevância nas ciências da educação. Os altos índices de repetência representam, além do atraso da vida escolar dos alunos que interferem diretamente em suas vidas e de suas famílias -, onerosos gastos públicos. Tal objeto de estudo ainda não tinha sido abordado na região do município de Lavras e pode representar possibilidades de visualização do fenômeno na região em comparação com dados de outros estados e municípios.

\section{Concepção de fracasso escolar}

O fracasso escolar como objeto de estudo apresenta facetas multivariadas. Analisando historicamente o fracasso escolar, nota-se que o termo sofre transformações substanciais na definição do seu próprio objeto, na teoria que o fundamenta e no método de pesquisa que o orienta. Na presente análise classificaremos o fracasso escolar conforme
Angelucci et al (2004), Marchesi et al (2004) e Asbahr e Lopes (2006) que realizaram ampla revisão de literatura sobre o tema, e Carvalho (2000) que difundiu uma leitura da temática com ênfase na relação entre família e escola.

Em revisão sistematizada da literatura, Angelucci et al. (2004) verificaram que a maioria dos estudos sobre o tema coloca o fracasso escolar como problema psíquico, ao qual se atribuem prejuízos emocionais e cognitivos na dificuldade do aluno em se ajustar à escola ou a características do ambiente escolar. Nesta perspectiva, o aluno é tomado como o único responsável pela sua situação, e a escola é vista como um ambiente ideal, no qual o aluno encontra todas as condições favoráveis para o desenvolvimento de seu potencial (ANGELUCCI et al., 2004).

Marchesi et al (2004) evidenciam, dentre outras fatores, a disposição e a motivação dos alunos como mais um dos fatores relacionado ao fenômeno do fracasso escolar, como sendo razão de preocupação dos professores. 
Marchesi et al (2004, p.28) expõem: "Mas talvez o que mais preocupa os professores seja a escassa motivação dos alunos.” Assim, à medida que a apatia discente é centrada pelos professores como fator de causalidade do fracasso, todo empenho e melhorias institucionais não repercutem na própria condução do aluno que independe do fator externo para tal.

Marchesi et al (2004) formulam que a experiência de fracasso escolar denota ao aluno um desapontamento, um estigma desencadeador da ausência de êxito. “A experiência de fracasso escolar os conduz a desconfiar de suas habilidades e a se considerar incapazes de ter êxito nas tarefas escolares. A perda de motivação para o estudo é inevitável” (p. 29).

Também se inserem no tema fracasso escolar questões biológicas e emocionais, revelando a ambivalência e a generalização das causas do fracasso, mais uma vez centrada no aluno. Estudo de Asbahr e Lopes (2006), embora reconheça a existência de questões psíquica/biológica/emocional, explicita que a lógica de causalidade biológica, embora delimite o portador, pode ser um artifício utilizado pelos docentes como esquiva da responsabilidade do ensino adequado, pois “ao se utilizarem dessa lógica para entender os problemas de aprendizagem, os professores tiram da sua alçada a responsabilidade pelo processo de escolarização das crianças e conclamam o saber médico a intervir nas questões educacionais” (p. 62).

Há ainda o entendimento do fracasso escolar como um problema técnico, que pressupõe que o fracasso escolar é produzido na e pela escola, entretanto, reduzido à ideia da falta de domínio da técnica correta pelo professor. Desta forma, desloca-se a causa do problema para outro conceito amplamente pesquisado em ciências da educação: a formação docente. Não apenas o professor é culpabilizado nesta perspectiva, mas se estende também às autoridades que não proporcionaram a formação técnica adequada (ANGELUCCI et al., 2004).

Angelucci (2004, p.61) afirma:

"[...] mas o foco muda de lugar: não se localiza nos problemas individuais dos alunos, mas na técnica de ensino do professor. Nesse sentido, leva-se em conta a escola na produção dos reveses da aprendizagem, mas reduzida a uma relação dual abstrata em uma escola abstrata, ou seja, desvinculadas da sociedade que as inclui.

O sistema educacional também exerce papel importante. A sensibilidade diante das dificuldades de aprendizagem, os recursos existentes, a preparação e motivação dos professores, a flexibilidade do currículo, a atenção dada aos alunos com maior risco de fracasso, novos programas para facilitar aprendizagem, todos são fatores que podem ser determinantes do fracasso escolar.

Marchesi et al (2004) afirma como possibilidade ao sistema frente à temática do fenômeno: “[...] o que permite incrementar o orçamento das escolas, reduzir o número de alunos por aula, aumentar os orientadores e os professores de apoio e cuidar mais e melhor do conjunto das escolas e dos serviços educativos [...] (p. 26)".

O fracasso escolar pode ser entendido como questão institucional, que pressupõe a presença do insucesso desde o início da instituição da rede de ensino público no Brasil. Nesta concepção, o entendimento do fracasso escolar se faz a partir da análise dos processos sociais que, orientados por uma lógica econômica capitalista, atravessam o cotidiano escolar e reproduzem, neste contexto, o modelo das relações sociais. Há nesta perspectiva uma crítica às políticas educacionais descompromissadas com a democratização do ensino e às instituições que excluem do ato educativo a participação de atores de outros setores sociais, como a comunidade 
local, os movimentos sociais e a família (ANGELUCCI et al., 2004). É indicativo de fracasso escolar vivências subalternas, ou seja, o contexto econômico e social do aluno e da instituição de ensino caracterizada por condições inferiores.

A existência relacional desse fator contextual, econômico e social como uma das nuanças causais do fenômeno de fracasso escolar é descrito por Marchesi et al (2004) quando afirmam: "Uma alta porcentagem de fracasso escolar tem sua origem direta nas carências econômicas, sociais e culturais que determinados grupos da população sofrem" (p. 23). A expressão mais nítida do vínculo relacional econômico e social no tocante ao fracasso escolar evidencia-se na existência da escola dual- pública / privada, pois em termos educacionais passíveis de medição, as escolas subalternas em recursos materiais apresentam resultados inferiores às escolas mais estruturadas em recursos. Portanto pauta-se em voga a regência do capitalismo até no acesso a saberes educacionais escolares, diluindo o fantasmagórico saber ideológico da igualdade no âmago de saberes.

Ainda, estudo de Asbahr e Lopes (2006, p.55) denotam que essa perspectiva em certo nível procede, todavia é um perigoso discurso que intenta tirar os outros apontamentos causais do fracasso escolar. Embora exista uma crítica no tocante às concepções de causalidade do fracasso centrada no aluno em seu constructo racial e econômico, ainda hoje essa concepção vigora, como observam os autores: "No entanto, essa ideia continua fortemente presente no dia-a-dia das escolas, na mente de professores, pais e dos próprios alunos" (p. 55).

De acordo com Marchesi (2004), há uma relação entre o nível socioeconômico e o rendimento, em conjunto com o contexto familiar e educacional, embora o contexto econômico e social nem sempre sejam determinantes. Para o autor "a maior renda per capita é apenas uma condição importante, mas não suficiente para conseguir melhores níveis educacionais" (p. 24). Ainda defende que o capital escolar dos pais, dependendo da forma como é transmitido, pode influenciar positivamente o progresso educacional dos filhos, da mesma forma que as expectativas dos pais também influenciam o rendimento dos alunos.

Nessa perspectiva, Carvalho (2000) faz um apontamento que evoca a casa do aluno e sua família: as políticas de dever de casa podem ser compreendidas como uma extensão da sala de aula, o que pressupõe o sucesso ou fracasso escolar dos alunos codependentes diretos das habilidades dos pais no ensino das matérias afins do cronograma escolar, ou seja, se os pais não forem bons docentes no lar ou não possuírem respaldos educacionais para tanto, certamente elucidará uma causalidade do fracasso escolar.

Com efeito, as políticas de dever de casa vêm redefinindo o lar como uma extensão da sala de aula e o dever de casa como uma tarefa a ser realizada fora do horário escolar, de preferência, em casa. Assim, o papel acadêmico atribuído à família nega a especificidade da educação escolar e afeta o papel profissional docente, contra toda uma história de diferenciação institucional, especialização funcional. Além disso, confunde o papel paterno/materno com o papel docente. (CARVALHO, 2000, p. 146-147).

Por fim, há o entendimento do fracasso escolar como questão política, que parte do princípio de que o próprio fracasso escolar pode ser uma maneira equivocada de rotular e problematizar um processo legítimo de reivindicação da transformação da estrutura educacional. Desta forma há uma ampliação 
nas relações causais que determinam a presença do fracasso escolar, não cabendo apenas à participação popular no processo educativo, mas à abertura da cultura dominante escolar para a cultura popular (ANGELUCCI et al., 2004).

\section{Um panorama sobre a repetência}

Para a sociedade e a comunidade educacional, a repetência é vista como um fenômeno típico do processo educacional, um problema de origem externa à escola e carente de soluções dentro da própria escola. Mas a repetência na maioria das vezes é consequência da baixa qualidade educacional, sendo compreendida como uma prática educacional para lidar com a não aprendizagem (TORRES, 2004).

A repetência acontece em maior número na África Subsaariana, no Caribe e na América Latina, sendo motivo de grande preocupação para a maioria dos países onde isso ocorre em maior número, como o Brasil, que ocupa o $2^{\circ}$ lugar no número de repetentes: cinco milhões de aluno por ano na Educação Básica. O fenômeno está concentrado nas primeiras séries e vinculado a problemas com a educação infantil, sobretudo com problemas com a linguagem escrita. Os critérios de qualificação e de aprovação são muitas vezes arbitrários, arcaicos, levando em consideração questões como a "maturidade escolar", assistência às aulas, disciplina e até mesmo higiene e aparência pessoal (Torres, 2004). Nesse sentido, num estudo com conselhos de classe de uma escola particular, Bonadiman (2009) constatou que os critérios para reprovação dos alunos se devem mais a fatores relacionados à cultura popular do que aos conhecimentos técnicos adquiridos durante a formação docente.
A difusão de questões de mobilização para a propagação de uma nova reformulação de saberes e práticas pode começar no âmago da concepção dos professores abarcada em ambiente de Conselho de Classe. Bonadiman (2009, p.85) afirma: "Em termos específicos, a análise do funcionamento do Conselho de Classe explicita lógicas próprias de funcionamento da instituição escolar e concepções de ensino- aprendizagem que possuem uma relação tênue com a cultura circundante”. A notoriedade da vinculação da concepção do Conselho de Classe, com atribuições valorativas inseridas nos ditames culturais, é um constructo a ser considerado para fins de uma reflexão crítica da própria prática e, sobretudo, da constituição dos saberes.

Bonadiman (2009) cunha o ideário de que o Conselho de Classe possui estreito vínculo com a cultura que o circunda para elaboração de concepções descritivas dos alunos, cultura esta que Mattos (2011, p.50) denomina “como um sistema de significados mediadores entre as estruturas sociais e a ação humana; segundo, por introduzir os atores sociais com uma participação ativa e dinâmica no processo modificador das estruturas sociais”.

\section{Metodologia}

\section{Procedimentos de coleta de dados}

De base multidisciplinar e qualitativa, a pesquisa utilizou os métodos que permitem a aglutinação de diferentes perspectivas teóricas em pedagogia. Foram realizadas observação participante e a análise temática do conteúdo dos registros produzidos pelo conselho de classe e pelos pesquisadores.

O trabalho de campo foi compreendido como um processo que vai além da coleta de dados, conforme proposto por González Rey (2002, p. 96). Para o autor, diferente da coleta de dados, "o trabalho de campo é um 
processo permanente de estabelecimento de relações e de construções de eixos relevantes de conhecimento dentro do cenário em que pesquisamos o problema”. Dessa forma, toda a informação a que temos acesso enquanto estamos em campo pode adquirir sentido para a pesquisa, caso convirja para o problema a que nos propomos resolver.

Foi importante, deste modo, uma descrição e a integração de elementos submetidos à pesquisa, além do conhecimento obtido através da vivência pessoal e de participação dos investigadores no contexto cultural de sua pesquisa.

O contato com nosso objeto ocorreu em três etapas: 1) estabelecimento de contato com a escola e com os professores; 2) participação na rotina das práticas escolares, de modo especial nos conselhos de classe; 3 ) registro de dados em diário de campo.

A abordagem etnográfica subsidiou a pesquisa tornando aspectos de estudos da desigualdade e exclusões estigmatizadas percebidas no exercício do Conselho de Classe e práticas docentes pautadas no contexto escolar.

\section{Definição dos participantes e parâme- tros de análise}

A pesquisa foi realizada na escola que propiciou disponibilidade. Na escola, participou-se das reuniões de conselho de classe do $6^{\circ}$ ao $9^{\circ}$ ano do Ensino Fundamental. O número médio de professores participantes dos conselhos foi oito. Tal fato não se configura como problema para definição da amostra, uma vez que o tema foi pouco explorado no município de Lavras e por tratar-se de pesquisa qualitativa e exploratória.

Os dados coletados passaram por uma análise temática do conteúdo e foram confrontados com os estudos problematizados na revisão da literatura, como forma de delinear e circunscrever as concepções docentes acerca do fracasso escolar. Foram construídas categorias presentes nos estudos de Angelucci et al (2004), Marchesi et al (2004) e Asbahr e Lopes (2006), que realizaram ampla revisão de literatura sobre o tema.

\section{Resultados}

Funcionamento e lógica do Conselho de Classe

Os professores se organizam ao derredor de uma mesa e explicitam espontaneamente a condição de aluno por aluno do $6^{\circ}$ ao $9^{\circ}$ ano do Ensino Fundamental, ao todo 122 alunos. As explicitações são realizadas com alguma ironia, não havendo uma lógica formal de tempo para a manifestação verbal de cada professor. Cada professor profere um juízo e nem sempre atenta para critérios previamente estabelecidos, subsistindo uma lógica de "vamos logo" e "estou com pressa, são muitos alunos”. Na reunião do Conselho de Classe faltaram professores, estando presentes oito. Houve explicitações verbais, que serão transcritas e analisadas a seguir, retiradas do Diário de Campo:

Prof1 - Aluno sumiu.

Prof2- Então põe ele em tudo. (referência a estudos orientados-recuperação)

Prof3-Reprova de uma vez, já que sumiu e nem deu satisfação.

Coordenadora pedagógica- $O$ sistema não permite reprovação direta, mas se ficar em tudo, por falta, certamente não passará.

Uma mãe ligou no momento da reunião para saber se o filho tinha sido aprovado ou reprovado. 
Coordenadora pedagógica- Nessas horas é a única participação da família na educação dos filhos, pois o ano todo tentou contatar essa mãe pra tratar questões disciplinares do filho.

Prof5- Nem os pais nem os filhos tem interesse na hora que precisa ter: no caso o ano todo sem vir.

Prof4- Os alunos têm preguiça até de caminhar na educação física.

Prof1-Aquele menino tem cara que tem problema.

Prof3-Se fosse cara estava bom, na realidade é o corpo todo, oh menino encapetado!

Prof7- Tem uma aluna que é uma gracinha e segue à risca minhas orientações!

Prof1- Essa é de Deus, nem tudo está perdido.

Prof6- Esse aluno não se interessa pela disciplina mesmo, mas até que ele é amigo de quase todos os professores! Vai com a cara, mas não vai com a matéria.

Prof8- Nesse caso já existe meio caminho andado, pelo menos.

Prof1- Essa aluna não vai aparecer pra recuperação...

Prof3- Deus te ouça! Recuperação em tudo por causa de falta. E tomara que não apareça o ano que vem. Nem pra repetir essa serve.

Prof2- Só ficava dormindo na aula, mas dei um empurrãozinho pra ser aprovado, é melhor ficar dormindo do que atrapalhar a aula.

Prof1- Essa garotada não quer saber de nada útil, somente a net com tudo de imprestável que tem lá.

A seguir serão explicitadas falas recorrentes sobre os alunos durante a realização do Conselho de Classe, também transcritas do Diário de Campo, (idem).
Aluno fraco; Esse deve ter trauma, pois ter um pai daquele não é saudável; Este é até bom se comparado ao irmão; Isso que dá namorar marginal; Esse menino tem problema de cabeça, ele acha que é ator famoso da Globo, nos estudos não acompanha nem tartaruga de desenho, ritmo muito lento na aprendizagem; É turista, quando vem a aula é só pra ver paisagem do lado de fora da sala; Aluno faltante; Só fala o que não precisa; Esse aluno é uma coisa; Não gosta de vir a escola; Esse menino tem vida sofrida ( referindo-se às condições emocionais e financeiras); Os pais não investem nos filhos, só investimentos supérfluos; Aluno PDI ${ }^{*}$, melhor que os normais; Aluno bom, um dos pouquíssimo; É triste chamar essa coisa de aluno. A gente ajuda quem se ajuda!

Após o término da reunião do Conselho de Classe, uma professora faz em lugar oculto aos olhos dos demais suas colocações afirmando que: Os professores não tiveram coragem de dizer tudo afinal, nas escolas do Estado a gente finge que ensina e os alunos fingem que aprendem e o Estado fica satisfeito com a mentira. Ninguém se importa! Viemos aqui pra receber o salário e pronto, e detalhe: salário ruim. Quando indagada sobre o método de fingimento do ensino, ela afirma e corrobora a fala de outros professores: $A$ gente ajuda quem se ajuda! Caso contrário, o método é esse.

A observação das falas de professores, diretores e coordenadora pedagógica propiciou uma visão ampliando o entendimento do que ocorre na sala de aula em função dos procedimentos adotados pelos professores e, sobretudo, como concebem o fenômeno de fracasso escolar.

\section{A ficha de avaliação do Conselho de Classe}

* Plano de Desenvolvimento Individual, necessário para alunos com deficiência. 
Além do Conselho de Classe, os professores, junto à coordenadora pedagógica, fazem reuniões semanais para discussão de uma proposta pedagógica de intervenção ao cenário contextual de cada turma. Todavia, quando questionada quanto à ausência de fichas com essas transcrições de intervenções bimestrais, a coordenadora afirma: A gente escreve uma vez só, no início do ano, já que nada muda, pois o que está ruim no começo fica até o fim! É mais fácil alunos bons ficarem ruins do que o oposto.
A referida ficha, conforme tabela 1 , contém as seguintes questões:

Tabela 1. Proposta e atividades desenvolvidas pela equipe pedagógica após reunião do conselho de classe.

1-Alunos com problemas de frequência.

2-Alunos indisciplinados.

3-Alunos com baixo rendimento escolar.

4-Alunos com problemas gerais (psicológicos, doenças emocionais, familiares etc...)

5-Resumo da turma (destaque pontos positivos e que necessitam de atenção):

As questões de 1 a 4 são respondidas citando nome e número dos alunos, a questão de número 5 é um parecer cursivo dos professores. Na questão de número 5, houve respostas conforme a tabela 2 :

Tabela 2. Respostas à questão de número 5 por série:

\section{$6^{\circ}$ ano:}

Prof5: Turma fraca, com baixo rendimento, requer muita atenção, pois o ritimo (ritmo) de aprendizagem é um pouco mais lento, e o ponto positivo é que a turma aceita bem novas propostas de reensino (são participativos)..

Prof3: Não estou conseguindo dar aula nessa turma, se Deus não olhar por mim, ficarei louco.

Prof2: A turma de modo geral é boa, tirando determinados alunos que atrapalham a aula. Alguns alunos são bons.

Coordenadora pedagógica e demais professores: Turma difícil com alunos com muita dificuldade. Precisa de intervenção e ajuda extraclasse.

$7^{\circ}$ ano:

Prof1: É muito agitada e a "coisa" só funciona no grito. Qualquer coisinha banal vira "bate-boca". Adoram falar palavras de baixo calão.

Prof2: Tem alunos que tem interesse em aprender e outros alunos sabem só conversar o tempo todo.

Coordenadora pedagógica e demais professores: Turma cheia, agitada, com alunos faltantes, difícil de trabalhar

e obter resultados.

$8^{\circ}$ ano:

Coordenadora pedagógica e demais professores: Falante e desinteressada. Dá muito trabalho, porém consigo controlar.

Prof8: Conversa muito, chega atrasado, grita dentro da sala de aula, não copia matéria. Tem alunos bons. 
$9^{\circ}$ ano

Coordenadora pedagógica e demais professores: Turma boa, um pouco desinteressada, mas boa de lidar. Grifo Prof1: Trabalha com facilidade, e apresenta um resultado consideravelmente positivo. Grifo Prof2: Pontos positivos por parte só dos interessados. Grifo Prof7 do $9^{\circ}$ ano do PAV (supletivo): Difícil trabalhar resgate de valores, pois a cultura trazida do bairro é difundida e reportada entre o corpo discente dentro das salas de aula.

O protocolo em que consta a participação da família nas atividades escolares aclara: Na reunião de pais e mestres realizada no dia 14/03/2012 para alunos do $7^{\circ}$ ao $9^{\circ}$ ano a participação dos pais foi:

- $7^{\circ}$ ano havia 41 alunos, e houve participação de 23 pais. (53,10\%).

- $8^{\circ}$ ano havia 24 alunos, e houve participação de 11 pais. (45,83\%).

- $9^{\circ}$ ano havia 40 alunos, e houve participação de 20 pais. (50\%).

Na reunião do Colegiado Escolar do $6^{\circ}$ ao $9^{\circ}$ ano, realizada no dia 22/03/2012 a participação foi escassa, todavia não documentada em números.

Para entrega dos boletins 04/06/2012 houve a seguinte participação:
- $6^{\circ}$ ano: 20 alunos e participação de 8 pais; (40\%).

- $7^{\circ}$ ano: 39 alunos e participação de 20 pais; (51,28\%).

- $8^{\circ}$ ano: 24 alunos e participação de 14 pais; (58,33\%).

- $9^{\circ}$ ano: 39 alunos e participação de 21 pais; (53,85\%).

\section{Análise da turma}

No final do ano letivo foi feita outra ficha intitulada Análise coletiva da turma, conforme tabela 3 :

Tabela 3. Análise coletiva da turma.

$\mathbf{6}^{\mathbf{0}}$ ano/ turno tarde/ 12/12/12. Assinada por toda direção.

$7^{\mathbf{0}}$ ano:

1- Como foi o desempenho da turma em geral no bimestre?

A turma de maneira geral teve um bom desempenho com exessão (exceção) de alguns alunos. (cinco alunos citados por nome).

2- Quais foram os pontos fortes da turma?

Bom desempenho por parte de alguns alunos (alunas)

3-Em que aspectos a turma precisa empenhar-se mais?

Mais leitura, participação e compromisso com os estudos.

4- Quanto às habilidades não consolidadas (PIP) como está sendo trabalhada?

Foi realizada na turma atividades de reensino, visando consolidar as habilidades do CBC.

$\mathbf{7}^{\mathbf{0}}$ ano/ turno tarde/ 12/12/12. Assinada por toda direção.

1- Como foi o desempenho da turma em geral no bimestre?

A turma é heterogênea onde alguns atrapalham com as conversas paralelas e outros excelentes sempre aguardando organização da turma. 


\begin{tabular}{|l|}
\hline 2- Quais foram os pontos fortes da turma? \\
Bom desempenho por parte de alguns alunos. \\
\hline 3- Em que aspectos a turma precisa empenhar-se mais? \\
Disciplina. \\
\hline 4- Quanto às habilidades não consolidadas (PIP) como está sendo trabalhada? \\
Foi realizada na turma atividades de reensino, visando consolidar as habilidades do CBC. \\
\hline $\mathbf{8}^{\mathbf{0}}$ ano/ turno tarde/ 12/12/12. Assinada por toda direção. \\
\hline 1- Como foi o desempenho da turma em geral no bimestre? \\
A turma de maneira geral teve um bom desempenho. \\
\hline 2- Quais foram os pontos fortes da turma? \\
São dedicados, unidos e participam ativamente de todas as aulas. \\
\hline 3- Em que aspectos a turma precisa empenhar-se mais? \\
Menos reclamação em relação aos professores. \\
\hline 4- Quanto às habilidades não consolidadas (PIP) como está sendo trabalhada? \\
Foi realizada na turma atividades de reensino, visando consolidar as habilidades do CBC \\
\hline $\mathbf{9}^{\mathbf{0}}$ ano/ turno tarde/ 12/12/12. Assinada por toda direção. \\
\hline 1-Como foi o desempenho da turma em geral no bimestre? \\
A turma de forma geral teve um bom desempenho. \\
\hline 2-Quais foram os pontos fortes da turma? \\
Bom desempenho por parte de alguns alunos. \\
\hline 3-Em que aspectos a turma precisa empenhar-se mais? \\
Mais leitura, e menos reclamação. Entretanto quando eles estão interessados são unidos e participam ativa- \\
mente. \\
\hline 4-Quanto às habilidades não consolidadas (PIP) como está sendo trabalhada? \\
Foi realizada na turma atividades de reensino, visando consolidar as habilidades do CBC. \\
\hline
\end{tabular}

A tabela 3 foi constada, todavia, não avaliada em virtude de ser um procedimento requerido pela inspetoria de educação; assim, as respostas foram mais formais e destinadas à demanda.

\section{Análise dos dados e considerações}

Em uma perspectiva multifatorial de nuances relativa e cambiante, os professores conceberam, na maioria, o aluno como causa do fracasso escolar, como problema psíquico biológico e emocional, e motivacional (Angelucci et al., 2004). Houve predominância de afirmações centradas na apatia e “desinteresse” advindos dos alunos. Nesta perspectiva o aluno é tomado como o único responsável pela sua situação, e a escola é vista como um ambiente ideal, no qual o aluno encontra todas as condições favoráveis para o desenvolvimento de seu potencial. Este resultado converge com as pesquisas de Marchesi et al (2004, p.28), em que se expõe: 
"mas talvez o que mais preocupa os professores seja a escassa motivação dos alunos.”

Corrobora essa afirmação de causalidade do fenômeno fracasso escolar centrado no aluno -em suas nuances- a própria ficha desenvolvida pela Equipe Pedagógica após reunião do Conselho de Classe, em que constam $80 \%$ das questões somente vinculadas à centralidade no aluno: 1) Alunos com problemas de frequência, 2) Alunos indisciplinados, 3) Alunos com baixo rendimento escolar e 4) Alunos com problemas gerais (psicológicos, doenças emocionais, familiares, etc.).

Apenas na quinta questão - Resumo da turma (destaque pontos positivos e que necessitam de atenção - é que há evidência de outra lógica, vinculado ao posicionamento dos docentes. Nas respostas analisadas pode-se perceber o aumentou da distinção entre “nós” e "eles”, em que não se postula qualquer proximidade das classes (professor/ aluno) nem se evoca uma reação pedagógica e/ ou didática por parte dos docentes, a qual, quando ocorreu, denota um sentido arbitrariamente excludente: Turma difícil com alunos com muita dificuldade. Precisa de intervenção e ajuda extraclasse. Antes, no tocante à quinta questão houve apenas leitura generalizada - "Conversa muito, chega atrasado, grita dentro da sala de aula, não copia matéria. Tem alunos bons”, em contrapartida às questões de 1 a 4 que vislumbrou "alunos problemas" por número e/ou nome. Todavia nas explicitações no Conselho de Classe, houve 100\% de apontamento causal no aluno em função de nuances psíquicas biológicas e emocionais, além de motivacionais e do apontamento da desestrutura da família dos alunos.

Observa-se que, para além da centralização do problema de aprendizagem apenas no aluno, há um apontamento técnico, ou seja, um problema técnico, que pressupõe que o fracasso escolar é produzido na e pela escola. Não apenas o professor é culpabilizado nesta perspectiva, mas ela se estende também às autoridades que não proporcionaram a formação técnica adequada (Angelucci et al., 2004), ou seja, faz-se apologia a uma formação técnica acadêmica insuficiente, ou aplicação inadequada da técnica pelo professor.

O sistema educacional também exerce papel importante: a sensibilidade diante das dificuldades de aprendizagem, os recursos existentes, a preparação e motivação dos professores, a flexibilidade do currículo, a atenção dada aos alunos com maior risco de fracasso, novos programas para facilitar aprendizagem, todos são fatores que podem ser determinantes do fracasso escolar. (MARCHESI, 2004).

Corrobora a dificuldade do manuseio da técnica ou formação em déficit as afirmações escritas dos docentes que pautaram: Não estou conseguindo dar aula nessa turma, se Deus não olhar por mim, ficarei louco; Precisa de intervenção e ajuda extraclasse; Turma cheia, agitada, com alunos faltantes, difícil de trabalhar e obter resultados. Afirmações essas que constaram 
apenas em três de 10 respostas transcritas, ou seja, 30\% das transcrições fizeram leve apontamento ao problema técnico. Nas afirmações, roga-se por Deus em virtude da insuficiência da técnica, clama-se pela extraclasse, pelo limitante do uso da técnica explicita-se o desabafo: difícil de trabalhar.

Outra categoria de causalidade do fracasso escolar pode ser entendida como questão institucional, que pressupõe a presença do fracasso a priori na instituição da rede de ensino público no Brasil. Nesta concepção, os processos sociais que, orientados por uma lógica econômica capitalista, atravessam o cotidiano escolar e reproduzem, neste contexto, o modelo das relações sociais. ANGELUCCI et al., 2004). É indicativo de fracasso escolar vivência subalternas, ou seja, o contexto econômico e social do aluno e da instituição de ensino caracterizada por condições inferiores (MARCHESI et al, 2004).

Houve apontamento desse fator na concepção docente, quando fundada crítica explicitou que o capital dos alunos, tanto cultural quanto financeiro, posicionava-se aquém do necessário nível do saber; no modelo de hipocrisia do sistema estatal de educação; no valor pago aos professores; na infraestrutura das salas para recepção dos alunos; na exposição da condição de determinado aluno e crítica ao sistema que, por questões financeiras (aluno custa aos cofres públicos), não permite reprovação direta. Asbahr e Lopes (2006) denotam que essa perspectiva em certo nível procede, todavia, é um perigoso discurso que intenta tirar os outros apontamentos causais do fracasso escolar. Embora exista uma crítica no tocante às concepções de causalidade do fracasso centrada no aluno em seu constructo racial e econômico, ainda hoje essa concepção vigora em todos os atores que, de alguma forma, pertencem ao universo escolar: os professores, os pais e os próprios alunos.

A estrutura familiar dos alunos foi apontada com unanimidade pelos professores à medida que afirmaram que a participação da família é precária, pois alguns até vão as reuniões, todavia "são tão desestruturados e que não passa de teoria, pois depois da reunião não dão notícia de nada”. "Alguns não cuidam nem da própria vida muito menos dos filhos"; "Nem os pais nem os filhos tem interesse na hora que precisa ter; os pais não investem nos filhos, só investimentos supérfluos”. A questão de número 4 da tabela 1 elucida essa ênfase: Alunos com problemas gerais (psicológicos, doenças emocionais, familiares etc...)

$\mathrm{O}$ apontamento da questão política somente foi constado em um sentido antagônico, ou seja, delineando oposição à abertura para cultura popular sobre os ditames do sistema dominante: Difícil trabalhar resgate de valores, pois a cultura trazida do bairro é difundida e reportada entre o corpo discente dentro das salas de aula. Essa transcrição discorre uma apologia de o valor cultural do bairro ser longínquo do "real resgate de valores”, pois se conota como "não valor”. 
Explicita-se, assim, que as portas de acesso a outras formas de cultura e a aceitação de uma cultura dada ainda se encontram cerradas.

Em suma, grande parte das explicitações de causalidade do fenômeno fracasso escolar ficou centralizada no aluno em diversas perspectivas - psíquica, biológica $e$ emocional, familiar e cultural. Apenas uma leve e conformada concepção do sistema regente como apático aos resultados reais. Apontamentos de questão institucional que abarcaram: o capital dos alunos, tanto cultural quanto financeiro, como aquém; um modelo do sistema estatal de educação distante das necessidades educativas; salário desvalorizado ante a laboriosa profissão docente; infraestrutura precária para recepção dos alunos; um sistema que, por custos públicos, não permite a reprovação direta, pressupondo ser necessária a reprovação dos alunos aquém das demandas escolares. Apontamento da questão política elucidou portas fechadas para a possibilidade de troca do dominante pelo popular, pautando a lógica de sistema educacional fixa. Portanto, aos alunos, em seu cotidiano, restou a adequação.

\section{Referências}

ASBAHR, F. da S. F. \& LOPES, J. S. “A culpa é sua”. Psicologia USP, 17(1), 53-73 São Paulo. 2006.

ANGELUCCI, C. B.; KALMUS, J.; PAPARELLI, R.; PATTO, M. H. S. O estado da arte da pesquisa sobre o fracasso escolar (1991-2002): um estudo introdutório.
Educação e Pesquisa, São Paulo, v. 30, n. 1, p. 51-72, Jan/Abr 2004.

BONADIMAN, H. L. Representações docentes sobre o processo ensino aprendizagem de alunos do ensino médio. Revista de Educação, Brasília n. 150, a. 38, jan./mar. 2009.

BRANDÃO, C. R. Diário de campo: a antropologia como alegoria. São Paulo: Brasiliense, 1982.

CARVALHO, M.E.P. de. Relações entre família e escola e suas implicações de gênero. Cad. Pesqui., São Paulo, n. 110, p. 143-155, julho, 2000.

GONZÁLEZ REY, F. L. Pesquisa qualitativa em psicologia: caminhos e desafios. São Paulo: Pioneira Thomson Learning, 2002.

MARCHESI, A; GIL, C. H. Fracasso escolar uma perspectiva multicultural. Porto alegre: Artmed, 2004.

MATTOS, C. L. G. de. A abordagem etnográfica na investigação científica. In: MATTOS, C. L. G. de e CASTRO, P. A. de (Orgs.). Etnografia e educação: conceitos e usos. Campina Grande: EDUEPB, 2011.

TORRES, R. Repetência escolar: falha do aluno ou falha do sistema. In: MARCHESI, A.; GIL, C. H. Fracasso escolar uma perspectiva multicultural. Porto alegre: Artmed, 2004.

\section{Agradecimentos}

Gostaríamos de agradecer ao professor Ismael Pereira de Siqueira, pela colaboração no desenvolvimento da pesquisa, aos professores do colégio que, gentilmente, aceitaram nossa participação nas reuniões e à Fundação de Amparo à Pesquisa 
do estado de Minas Gerais - FAPEMIG. 